\title{
miR-143 acts as a novel Big mitogen-activated protein kinase 1 suppressor and may inhibit invasion of glioma
}

\author{
WEI-YI CHEN ${ }^{1,2^{*}}$, ZHI-QIANG LANG ${ }^{2 *}$, CHAO REN $^{3 *}$, PING YANG $^{2}$ and BAOGANG ZHANG ${ }^{1}$ \\ ${ }^{1}$ Department of Pathology, Weifang Medical University, Weifang, Shandong 261053; Departments of ${ }^{2}$ Pathology and \\ ${ }^{3}$ Neurology, Affiliated Yantai Yuhuangding Hospital of Qingdao University, Yantai, Shandong 264000, P.R. China
}

Received June 4, 2018; Accepted June 12, 2019

DOI: 10.3892/or.2019.7218

\begin{abstract}
Upregulation of the Big mitogen-activated protein kinase (BMK)1 has been reported in glioma and other epithelial tumors. In addition, the decreased expression of BMK1 inhibits tumorigenesis, leading to the broad consensus that it functions as cell-autonomous epithelial tumor promoter. Using two online miRNA target prediction databases, microRNA (miR)-143 was predicted as the potential miRNA regulator of BMK1. RNA immunoprecipitation analysis and Luciferase reporter assay showed that miR-143 binds to the 3' untranslated region of BMK1. Notably, the expression of miR-143 has a strong association with the World Health Organization grade and survival rates in patients with glioma by statistical analysis. Furthermore, miR-143 inhibited glioma cells migration and invasion through cytoskeletal rearrangement in vitro and in vivo through matrigel invasion assay, scratch assay, cellular F-actin measurement, chemotaxis assay and intracranial brain tumor xenografts. Finally, DNA methylation assay showed that the downregulation of miR-143 was due to hypermethylation of its promoter region. These results reveal that miR-143 represents a potential therapeutic target in glioma by modulating BMK1.
\end{abstract}

\section{Introduction}

Glioma is the most common primary malignant tumor of the central nervous system in adults. Despite modern diagnosis and treatment, prognosis of the disease remains poor, with the median survival time ranging from 12-14 months (1). The local tissue destruction caused by the invasion of glioma cells within the brain is often lethal. This is the cause of high

Correspondence to: Dr Baogang Zhang, Department of Pathology, Weifang Medical University, 7166 Baotong Street, Weifang, Shandong 261053, P.R. China

E-mail: zhangbg@wfmc.edu.cn

${ }^{*}$ Contributed equally

Key words: microRNA-143, invasion, glioma, big mitogen-activated protein kinase 1 morbidity and mortality of malignant glioma $(2,3)$. Identifying novel molecules that can repress the invasiveness and metastasis of glioma cells will facilitate the development of novel anti-glioma strategies.

Big mitogen-activated protein kinase 1 (BMK1) is a newly identified member of the mitogen-activated protein (MAP) kinase family (4). In our previous research, it was demonstrated that BMK1 was upregulated and associated with invasion in glioma (5). Furthermore, BMK1 is also overexpressed in melanoma (6) and hepatocellular carcinoma (7). However, the role of BMK1 in the molecular pathogenesis of glioma remains largely unknown.

MicroRNAs (miRNA/miRs) are a class of small, noncoding single-stranded RNAs that modulate gene expression at the post-transcriptional level (8). Notably, previous studies have shown that miRNAs serve a similar role to oncogenes or tumor suppressors by regulating the signaling pathways involved by the target gene and by regulating the formation and development of tumors $(9,10)$. miRNAs downregulate gene expression by binding to the 3'-untranslated regions (UTRs) of the target mRNAs $(8,11)$. A single miRNA may have hundreds of target genes that regulate about 200 protein-coding genes. In terms of the number of confirmed miRNAs, they regulate the expression of $\sim$ one-third of the protein-coding genes (12). Additionally, previous studies provide evidence that certain miRNAs can function as potential biomarkers for cancer diagnosis, progression, and response to treatment $(13,14)$.

miR-143 is located on chromosome 5 position 33 in the human genome. This miRNA is highly expressed in the colon and is consistently reported as being downregulated in the colorectal adenocarcinoma (15). Subsequent studies have confirmed that miRNA-143 inhibits cell proliferation, invasion and metastasis by regulating multiple target genes (16-18). Of particular interest to us, similar findings have been reported in pancreatic cancer, breast cancer, and other solid tumors of epithelial origin $(19,20)$. However, the functions of miR-143 in the glioma that underlie their presumed tumor suppressor activity have not been investigated.

The purpose of the present study was to explore the association between BMK1 and miR-143. In the present study, it was demonstrated that miR-143 acts as a novel BMK1 inhibitor that is a valuable prognostic marker for patients with glioma. The in vitro and in vivo results indicate that miR-143 is significantly involved in glioma invasion and metastasis and 
the expression of miR-143 is repressed by methylation of its promoter. The present study may provide a therapeutic target molecule for malignant glioma infiltration.

\section{Materials and methods}

Cell culture and reagents. The human cell lines U87 and HEB were obtained from the American Type Culture Collection (Manassas, VA, USA) and were cultured in Roswell Park Memorial Institute medium (RPMI)-1640 (HyClone; GE Healthcare, Chicago, IL, USA), supplemented with $10 \%$ fetal bovine serum (FBS; HyClone; GE Healthcare) and $100 \mu \mathrm{g} / \mathrm{ml}$ penicillin/streptomycin in a humidified atmosphere of $37^{\circ} \mathrm{C}$ and $5 \% \mathrm{CO}_{2}$. Notably, U87 cell line was recognized as glioblastoma cell line of unknown origin. The human glioma cell lines U251 (TCHu 58) and SHG44 (TCHu 48) was purchased from the cell bank of the Chinese Academy of Sciences. All cell lines have been authenticated by STR profiling.

Patients and tissue specimens. A total of 176 paraffin-embedded samples and 30 pairs of surgically resected fresh glioma tissues including their corresponding adjacent non-cancerous tissues were collected from the Affiliated Hospital of Weifang Medical University and the Affiliated Yantai Yuhuangding Hospital of Qingdao University from 2008-2015. The detailed information of 176 patients with glioma is listed in Table I. The inclusion criteria for the patients is that they had gliomas and had agreed to participate in the study. Samples were collected following a protocol approved by the Institutional Review Board, and patients gave their consent for the research of their tissue specimens in the present study. The study protocol was reviewed and approved by the Weifang Medical University Ethics Committee (approval no 99, 11-November-2016).

miRNA prediction. Two online miRNA prediction databases (www.microrna.org/microrna/home.do and www.targetscan. org) were used. These were searched for BMK1 and found that miR-143 was the most potential regulator.

$R N A$ extraction and reverse transcription-quantitative polymerase chain reaction $(R T-q P C R)$. RNA extraction and RT-qPCR was performed as previously described (21). Total miRNA from cultured cells, surgically resected fresh tissues, and paraffin-embedded glioma specimens was extracted using the mirVana miRNA Isolation kit (Ambion; Thermo Fisher Scientific, Inc., Waltham, MA, USA) and RecoverALL Total Nucleic Acid Isolation kit (Ambion; Thermo Fisher Scientific, Inc.) according to the manufacturer's protocol. Complementary DNA was synthesized with $5 \mathrm{ng}$ of total RNA using the TaqMan miRNA Reverse Transcription kit (Applied Biosystems; Thermo Fisher Scientific, Inc), and the expression levels of miR-143 were measured using Hairpin-itTM miRNAs qPCR Quantitation kit (Shanghai Genepharma, Co, Ltd., Shanghai, China). Reaction conditions: $95^{\circ} \mathrm{C}$ for $30 \mathrm{sec}$, $95^{\circ} \mathrm{C}$ for $3 \mathrm{sec}, 60^{\circ} \mathrm{C}$ for $30 \mathrm{sec}$, a total of 40 cycles. miR-143 reverse transcription primer sequences: Forward, 5'-TGT AGTTTCGGAGTTAGTGTCGCGC-3'; reverse, 5'-CCTACG ATCGAAAACGACGCGAACG-3'. U6 primer sequences: Forward, 5'-GTTTTTTGTAGTTTTTGGAGTTAGTGTTGT
GT-3'; reverse, 5'-CTCAACCTACAATCAAAAACAACA CAAACA-3'. U6 was used as an internal reference. Primers used for BMK1: Forward, 5'-CTGGCTGTCCAGATGTGA A-3'; reverse, 5'-ATGGCACCATCTTTCTTTGG-3'. Analysis of relative gene expression data using RT-quantitative PCR and the $2^{-\triangle \Delta C q}$ method (22).

Bisulfite sequencing and DNA methylation. Genomic DNAs from NHA and glioma cell lines (the cell density reached $90 \%$ confluency) were isolated using TRIzol reagent (Invitrogen; Thermo Fisher Scientific, Inc.) and Genomic DNAs from fresh glioma tissues were isolated using the DNeasy Blood and Tissue kit (Qiagen, Valencia, CA, USA) according to the manufacturer's protocol. Bisulfite sequencing was performed as previously described (23). DNA methylation analysis was performed using Epigenetek Methylflash Methylated DNA quantification kit (cat. no. P1034 \pm 48 ) following the manufacturer's protocol.

Plasmid, retroviral infection, and transfection. miR-143 mimics (miR-143) oligonucleotides (3'-CUCGAUGUCACG AAGUAGAGU-5'), miR-143 inhibitor (Ant-miR) oligonucleotides (3'-UGGUCUCUACGUCGUGACGUGG-5') and miR-143 mutant oligonucleotides (3'-AUGUGUCUU AUGCAAGCUCGCA-5') were synthesized by GenePharma (Shanghai, China). They were transfected into glioma cell lines by using Lipofectamine 2000 (Invitrogen; Thermo Fisher Scientific, Inc.) at a final concentration of $50 \mathrm{nM}$ according to the manufacturer's protocol. A DNA fragment containing the hsa-miR-143 precursor with 300 bp flanking sequence of each side was amplified into retroviral transfer plasmid pMSCV-puro (Shanghai GenePharma). A blank plasmid was used as a negative control (NC). The open reading frames of BMK1 genes generated by PCR were cloned into retroviral vector pMSCV-neo (Clontech Laboratories, Inc., Mountainview, CA, USA). Retroviral production and infection were performed as previously described (24). The 3'UTRs of BMK1 were amplified and cloned into the downstream region of a luciferase gene in a modified pGL3 control vector (Promega Corporation, Madison, WI, USA), as described previously (25).

The U251/miR-143 cells were transfected with pMSCVneo-BMK1 plasmid or pMSCV-neovectorusing Lipofectamine ${ }^{\circledR}$ (Invitrogen, Carlsbad, CA, USA) following the manufacturer's protocol. Briefly, the cells were plated at a density of $5 \times 10^{5}$ cells/well in a 6 -well plates to grow overnight, and then they were transected with $4 \mu$ g plasmid using Lipofectamine ${ }^{\circledR} 2000$ (Invitrogen; Thermo Fisher Scientific, Inc.) following the protocol. After transfection, cells were cultured at $37^{\circ} \mathrm{C}$, $5 \% \mathrm{CO}_{2}$, overnight. Then cells were trypsinised, diluted and reseeded into $10 \mathrm{~cm}$ culture dishes. Single cell clones were isolated for clone expansion. Stable transfected cell clones were named U251/miR-143+BMK1 and U251/miR-143+CON cells.

Western blot analysis. Western blot analysis was carried out using standard methods. After treatment, the cells were treated with lysis buffer (Cell Signaling, Danvers, MA, USA) on ice for $20 \mathrm{~min}$. Subsequently, the cell lysates were centrifuged at $1,5000 \times \mathrm{g}$ at $4^{\circ} \mathrm{C}$ for $30 \mathrm{~min}$, the supernatant was collected 
Table I. Clinicopathologic characteristics of patients with glioma.

\begin{tabular}{lr}
\hline Patient characteristics & $\mathrm{n}(\%)$ \\
\hline Sex & \\
Male & $99(56.2)$ \\
Female & $77(43.7)$ \\
Age (years) & \\
$<40$ & $81(46.0)$ \\
$40-49$ & $37(21.0)$ \\
$50-59$ & $27(15.3)$ \\
$60-69$ & $25(14.2)$ \\
$70-79$ & $6(3.4)$ \\
WHO grading & \\
Grade I (pilocytic astrocytoma) & $24(13.6)$ \\
Grade II & $53(30.1)$ \\
Grade III & $56(31.8)$ \\
Grade IV & $43(24.4)$ \\
Patient survival & \\
Alive & $34(19.3)$ \\
Deceased & $142(80.7)$ \\
\hline
\end{tabular}

WHO, World Health Organization.

as the total cellular protein extract. The total protein extract was quantified by using the BCA protein assay kit (Pierce, Rockford, IL, USA). Equal amounts of protein (10 $\mu \mathrm{g} / \mathrm{lane})$ were separated on $10 \%$ SDS-polyacrylamide gel and transferred onto nitrocellulose membranes. The membrane was incubated for $2 \mathrm{~h}$ in PBS plus $0.1 \%$ Tween-20 and 5\% non-fat skim milk to block non-specific binding. The following antibodies were used in the present study: BMK1 (cat. no. sc-81460, 1:1,000; Santa Cruz Biotechnology, Inc., Dallas, TX, USA), phosphorylated (p)-cofilin (cat. no. sc-21867-R, 1:1,000; Santa Cruz Biotechnology, Inc.), cofilin (cat. no. sc-53934, 1:1,000; Santa Cruz Biotechnology, Inc.), $\beta$-actin (4970, 1:1,000; Cell Signaling Technology, Inc.), and the secondary antibody: Horseradish peroxidase-linked anti-mouse IgG antibody (cat. no. 58802, 1:2,000; Cell Signaling Technology, Inc. Danvers, MA, USA). A reference housekeeping protein $(\beta$-actin) was used to normalize the average protein expression. All experiments were repeated at least three times. After incubated with antibodies, the membranes were placed into TBST (10 mM Tris-HCL, $150 \mathrm{mM} \mathrm{Nacl}$ and $0.05 \%$ Tween-20, $\mathrm{pH}=7.6$ ), and shaken for $5 \mathrm{~min}$ at room temperature for 3 times. Western blots were visualized by using enhanced chemiluminescence reagents (Pierce; Thermo Fisher Scientific, Inc.) The protein band intensity was quantified using the ImageJ 1.44p software (https://imagej.nih.gov/ij/download.html).

Cell viability assay. Cell viability was detected via MTT assays (Sigma; Merck KGaA, Darmstadt, Germany). All experiment steps were performed using $2 \times 10^{3}$ of cells seeded on 96-well plates. After the cells were cultured for different time points, the culture medium was removed. Subsequently, the cells were incubated with MTT solution (50 $\mu \mathrm{l}$ of $2 \mathrm{mg} / \mathrm{ml}$ MTT powder in PBS; $100 \mu 1 \mathrm{RPMI}-1640$ containing $10 \% \mathrm{FBS}$ ) at $37^{\circ} \mathrm{C}$ for $4 \mathrm{~h}$. Subsequently, the culture medium was removed and DMSO (150 $\mu \mathrm{l}$; Sigma; Merck KGaA) was added into each well for $30 \mathrm{~min}$ until all crystals were dissolved. The absorbance was directly proportional to the number of viable cells.

Chemotaxis assay. Chemotaxis assay was performed as described previously (26). Briefy, IGF-1 was loaded into the lower chemotaxis chamber and $5 \times 10^{5}$ cell $/ \mathrm{ml}$ cells were added to the upper chambers. The polycarbonate filter (Neuroprobe, Cabin John, MD, USA) was inserted between the chambers. The number of migrating cells were counted. Chemotaxis index=the migrating cell number in a chemo-attractant gradient/the migrating cell number in a medium control.

Cellular F-Actin measurement. The F-actin content was done as described previously (27). After reaching 70-80\% confluency, U87 cells were followed by the stimulation of $50 \mathrm{ng} / \mathrm{ml}$ IGF- 1 at $37^{\circ} \mathrm{C}$ at different time points. Then the cells were fixed, permeabilized, and incubated with Oregon Alexa-Flour 568 phalloidin at room temperature for $2 \mathrm{~h}$. After washing 5 times, the labeled phalloidin was extracted by using methanol at $4^{\circ} \mathrm{C}$ for $90 \mathrm{~min}$. The fluorescence was captured at $\mathrm{Ex} / \mathrm{Em}$ $578 / 600 \mathrm{~nm}$ in each sample and normalized against the total protein content as analyzed by a BCA kit (Pierce; Thermo Fisher Scientific, Inc.).

Scratch assay. The control cells and cells transfected with miR-143 mimic $\left(2 \times 10^{5} / \mathrm{ml}\right)$ were seeded in 6-well plates. $48 \mathrm{~h}$ later, cross lines were made using a $200 \mu \mathrm{l}$ sterile pipette tip. At $0,6,12,18,24 \mathrm{~h}$, the cells were imaged by using a Olympus inverted microscope (CH-BI45-T; Olympus). Experiments were repeated three times.

Matrigel invasion assay. A Boyden chamber invasion assay was performed as described previously (28). The glioma cells in serum-free RPMI-1640 at a density of $2 \times 10^{5}$ cells $/ \mathrm{ml}$ were loaded on the membrane in the upper chamber. All assays were repeated at least three times independently.

Luciferase reporter assay. To investigate whether miR-143 directly regulates BMK1 expression, the sequence of the 3 '-UTR of BMK1 was inserted downstream of a Renilla luciferase open reading frame. A total of $100 \mathrm{ng}$ pGL3-BMK1-3'UTR plasmid, 1ng pRL-TK renilla plasmid (Promega, Madison, WI, USA) and miR-143 mimics or miR-NC (Thermo Fisher Scientific, Inc.) were transfected into cells using Lipofectamine ${ }^{\circledR} 2000$ (Invitrogen; Thermo Fisher Scientific, Inc.). At $48 \mathrm{~h}$ after transfection, the activity of firefly luciferase was measured by using the Dual-Luciferase reporter assay kit (Promega, Madison, WI, USA). The data were normalized with Renilla luciferase activity.

RNA immunoprecipitation (RIP). Immunoprecipitation of miRNA ribonucleoprotein (miRNP) with anti-Ago1 (1:3,000; cat. no. ab5070; Abcam, Cambridge, UK) or IgG (1:2,000; cat. no. ab97051; Abcam) was performed as previously described (29). The RNA that was immunoprecipitated with anti-Agol or IgG antibodies was extracted using TRIzol LS 
(Invitrogen; Thermo Fisher Scientific, Inc.) as described previously (30).

Intracranial brain tumor xenografts and $H \& E$ staining. Adult male Sprague-Dawley rats $(n=16)$ weighing between 200-250 g were purchased from Wei Tong Li Hua experimental animal Co. (Beijing, China). Intracranial brain tumor xenografts were established with U87/NC $\left(5 \times 10^{5}\right)$ and U87/miR-143 $\left(5 \times 10^{5}\right)$ stereotactically implanted into the brain of four-week-old male severe immunodeficient mice with eight mice per group. The study protocol was reviewed and approved by Weifang Medical University Ethics Committee (approval no 129, 11-November-2016). Using a microliter syringe connected to the manipulating arm of the stereotactic apparatus, glioma cells were injected into the caudate nucleus at a depth of 4.0-4.5 $\mathrm{mm}$ from the dura. The glioma-enduring mice were euthanized 30 days after tumor cell injection, and the whole brains were removed. The maximum diameter of the tumor was about $1 \mathrm{~cm}$. Subsequently, paraffin-embedded tissues were sectioned into $5 \mu \mathrm{m}$ slices and subjected to $\mathrm{H} \& \mathrm{E}$ staining. H\&E staining was performed as described previously (31). The tissue slices were stained in hematoxylin for $5 \mathrm{~min}$ and in eosin for $10 \mathrm{sec}$. All the procedures were performed at room temperature. The images were captured using a light microscope system (Olympus Corporation, Tokyo, Japan).

5-AZA-2-deoxycytidine treatment. Glioma cells were seeded in $10 \mathrm{~cm}$ dishes $\left(1 \times 10^{6}\right.$ cells per dish) one day before drug treatment. The cells were treated with 1uM 5-AZA-2-deoxycytidine (5-AZA-dC; Sigma; Merck KGaA) every $24 \mathrm{~h}$ for 3 days.

Statistical analysis. All statistical analyses were performed using SPSS 13.0 statistical software package (SPSS, Inc., Chicago, IL, USA). The $\chi^{2}$ test was used to analyze the association between miR-143 expression and clinicopathologic characteristics. Survival curve was evaluated using the Kaplan-Meier method and differences were assessed using the log-rank test. Statistical significance for comparisons between groups was determined using two-tailed unpaired Student's t-test or analysis of variance. Multiple comparison between the groups was performed using S-N-K method, following ANOVA. $\mathrm{P}<0.05$ was considered to indicate a statistically significant difference.

\section{Results}

miR-143 is predicted to target $B M K 1$. To investigate the potential miRNA regulators of BMK1 which was known to be overexpressed in glioma (5), two online miRNA target prediction databases were used (miRNA.org; www.microrna.org and Targetscan; www.targetscan.org), and miR-143 was selected as the most potential regulator (Fig. 1A). Paired glioma (T) and adjacent non-tumor tissues (ANT) were comparatively evaluated by RT-qPCR analysis, with each pair obtained from the same patient. The results showed miR-143 expression was downregulated in 30 pairs of glioma tumor tissues compared with their ANT (Fig. 1B). Furthermore, similar results were found in glioma cell lines and normal brain glial cell line (NHA; Fig. 1C). In contrast, the expression of BMK1 in
Table II. Association between clinicopathologic features and expression of miR-143 in patients with glioma.

\begin{tabular}{lccr}
\hline & \multicolumn{2}{c}{ miR-143 expression } & \\
\cline { 2 - 2 } Patient characteristics & Low/none & High & P-value \\
\hline Sex & & & 0.651 \\
Male & 61 & 38 & \\
Female & 50 & 27 & \\
Age(years) & & & 0.377 \\
$\leq 45$ & 66 & 43 & \\
$>45$ & 45 & 22 & \\
WHO grade & & & $<0.001$ \\
I and II & 33 & 44 & \\
III and IV & 78 & 21 & \\
Survival & & & 0.031 \\
Alive & 16 & 18 & \\
Deceased & 95 & 47 & \\
\hline
\end{tabular}

miR, microRNA; WHO, World Health Organization.

glioma cell lines was higher than that in NHA (Fig. 1D). These data suggested that the expression of miR-143 in glioma was significantly reduced.

Decreased expression of miR-143 is associated with the clinicopathological features of glioma. In order to further understand the association between miR-143 expression and clinicopathological features of glioma, the expression levels of miR-143 in 176 paraffin-embedded glioma samples was examined by RT-qPCR. The detailed information of 176 glioma patients is listed in Table I. It was found that miR-143 expression was strongly associated with World Health Organization (WHO) grade (32) and the survival status of glioma patients, but not with age and sex (Table II).

In addition, Kaplan-Meier analysis using log-rank test was performed to assess the effect of miR-143 expression on the survival of patients. Patients with tumors exhibiting low miR-143 expression had shorter overall survival than those with high expression of it $(\mathrm{P}<0.05$, Fig. 1E). The median survival time of patients with low miR-143 expression (14 \pm 1.497 months, 95\% confidence interval: $11.065-16.935)$ was significantly shorter than those with high miR-143 expression $(35 \pm 3.527$ months, 95\% confidence interval: 28.087-41.913). Furthermore, similar results were found in either WHO grade I+II subgroup $(\mathrm{P}<0.05$, Fig. $1 \mathrm{~F})$ or grade III+IV subgroup $(\mathrm{P}<0.05$, Fig. 1G). Taken together, these results demonstrated that miR-143 could be a valuable prognostic marker for glioma patients at all disease stages, but this needs to be confirmed with larger sample size.

miR-143 directly targets $B M K 1$. To verify our assumption that miR-143 could regulate the expression of BMK1, firstly miR-143 expression was analyzed by RT-qPCR after being transfected with negative control (NC), miR-143 mimic (miR-143), miR-143 inhibitor (Ant-miR), and miR-143 mutant 
A BMK1 3'UTR 5' ...AUUCUGCAG -G- UUCAUCUCA... 3'

miR-143 3' CUCGaÚgucacgaAguagagu 5'
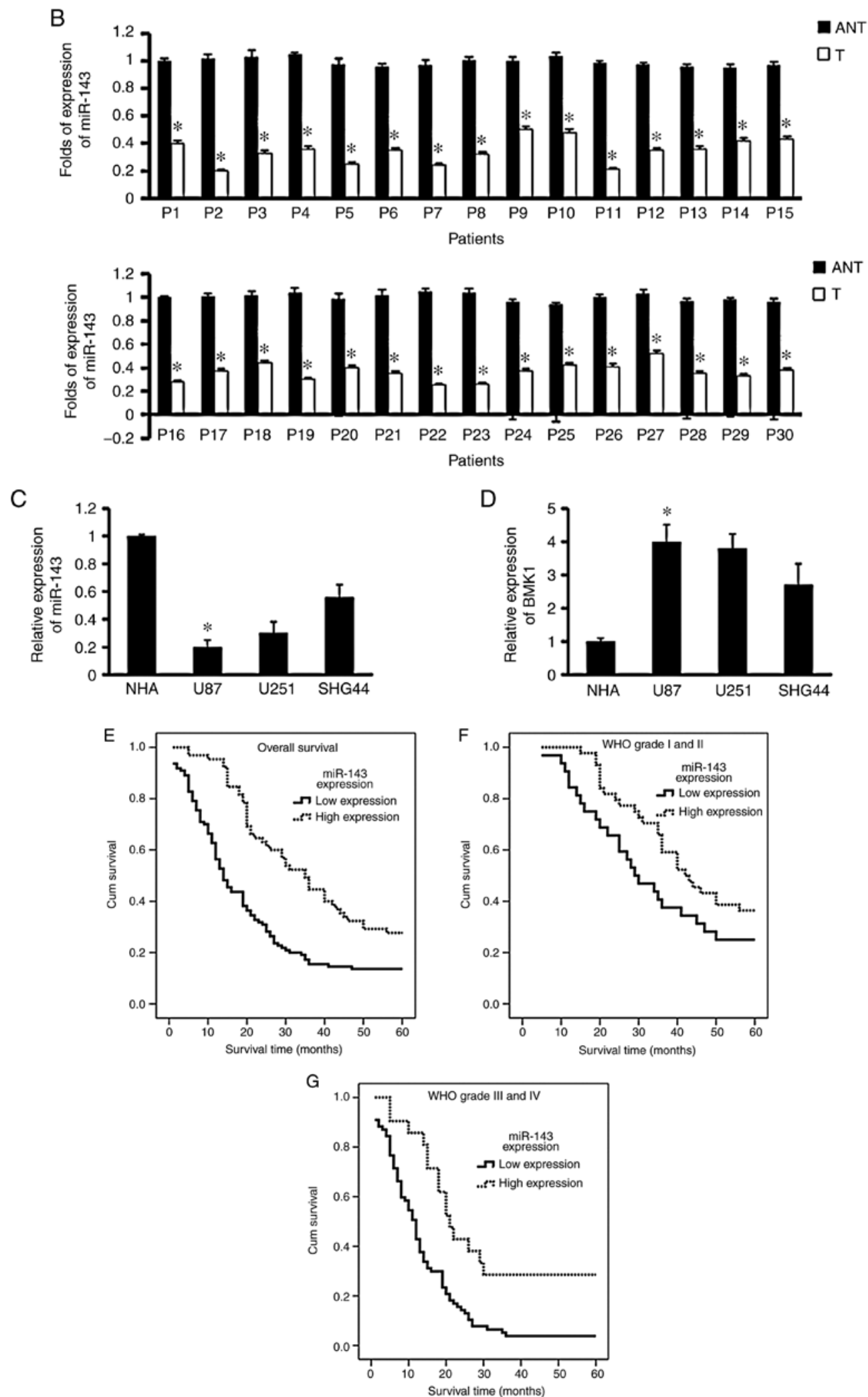

Figure 1. miR-143 expression in glioma tissues and cell lines. (A) miR-143 expression in glioma tissues and cell lines predicted binding of miR-143 to 3'UTRs of BMK1. (B) Expression of miR-143 in pairs of glioma tumor tissues (T) compared with their corresponding adjacent non-cancerous tissues (ANT). (C) RT-qPCR analysis of miR-143 expression in cultured human normal brain glial cell lines (NHA) and glioma cell lines (U87, 251, and SHG44). (D) RT-qPCR analysis of BMK1 expression in cultured human normal brain glial cell lines (NHA) and glioma cell lines (U87, 251, and SHG44). Kaplan-Meier analysis of the association (E) between the miR-143 expression levels and overall survival of patients with glioma with high ( $\mathrm{n}=65)$ and low $(\mathrm{n}=111)$ miR-143 expression; (F) between the miR-143 expression levels and survival of patients with glioma in the stage I and II subgroup; and (G) between the miR-143 expression levels and survival of patients with glioma in the stage III and IV subgroup. "P<0.05. Data are presented as the mean \pm standard deviation from three independent experiments. BMK, big mitogen-activated kinase; miR-143, microRNA; RT-qPCR, reverse transcription-quantitative polymerase chain reaction; WHO, World Health Organization. 


\section{A}

miR-143 $\quad 3^{\prime}$...CUCGAUGUCACGAAGUAGAGU... $5^{\prime}$

miR-143 mutant $3^{\prime}$...CUCGAUGUCACGAAGCGUUGU... 5'
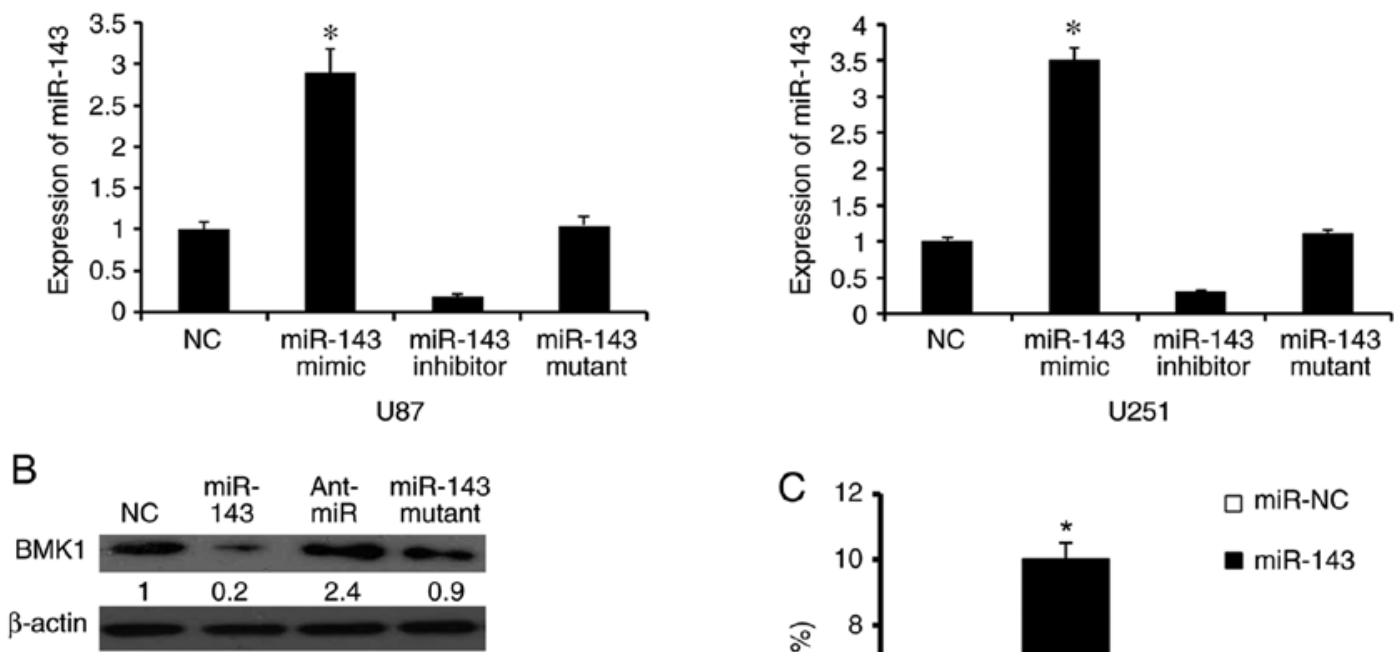

U87

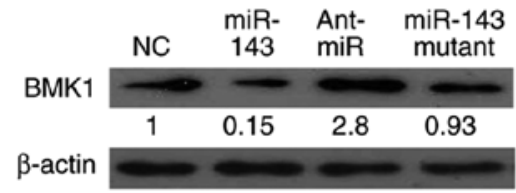

U251
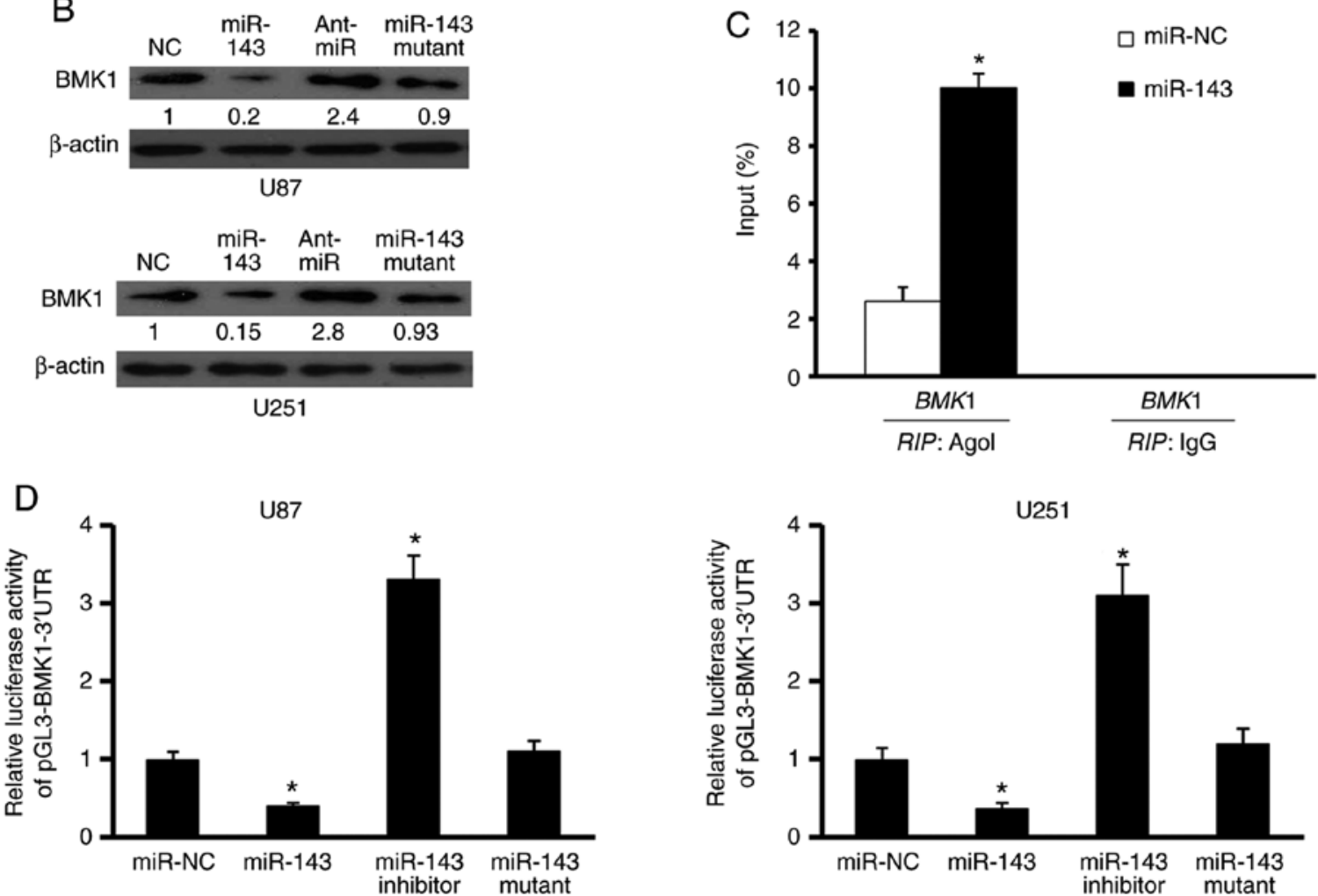

Figure 2. BMK1 is modulated by miR-143. (A) miR-143 and miR-143 mutant oligonucleotides. Predicted binding of miR-143 to 3'UTRs of BMK1. reverse transcription-quantitative polymerase chain reaction of miR-143 expression in U87 and U251 cells transfected with NC, miR-143 mimic, miR-143 inhibitor and miR-143 mutant. (B) Western blot analysis of BMK1 expression in transfected U87 and U251 cells. (C) The RNA immunoprecipitation analysis revealed recruitment of BMK1 mRNAs to miRNA nucleoprotein complex following immunoprecipitation against Agol. The IgG immunoprecipitation was used as the negative control. (D) Luciferase activity of pGL3-BMK1-3'UTR reporter in indicated cells co-transfected with the relevant oligonucleotides. Data are presented as the mean \pm standard deviation from three independent experiments. " $\mathrm{P}<0.05$. Ago1, argonaut; BMK, big mitogen-activated kinase; Ig, immunoglobin; miR, microRNA; NC, negative control; UTR, untranslated region.

in the U87 and U251 cell lines respectively, and obtained the stable transfected cell lines (Fig. 2A). BMK1 protein levels were significantly reduced in miR-143 mimic transfected cells but elevated in miR-143 inhibitor transfected cells compared with those in the corresponding control cells (Fig. 2B). Furthermore, RIP analysis following miR-143 transfection indicated that mRNAs of BMK1 could be specifically recruited to the miRNP complex isolated by anti-Agol antibody (Fig. 2C). Based on these results, it may be hypothesized that miR-143 targets BMK1 in glioma, in vitro.

To further investigate whether this regulation is due to the fact that miR-143 binds to the 3'UTR of BMK1, the 3'UTR of BMK1 was cloned downstream of a luciferase reporter gene (wt-BMK1) and wt-BMK1 vector and negative control, miR-143, miR-143 inhibitor, or miR-143 mutant were co-transfected into U87 and U251 cells. miR-143 regulated BMK1 expression through a significant reduction or addition of luciferase activity in cells transfected with miR-143 mimic or miR-143 inhibitor, respectively, compared with control cells (Fig. 2D). However, it was observed that relative luciferase activity was normal in cells co-transfected with BMK1 3'UTR and miR-143 mutant. Taken together, these results indicated that miR-143 can regulate directly BMK1 expression in glioma cells. 

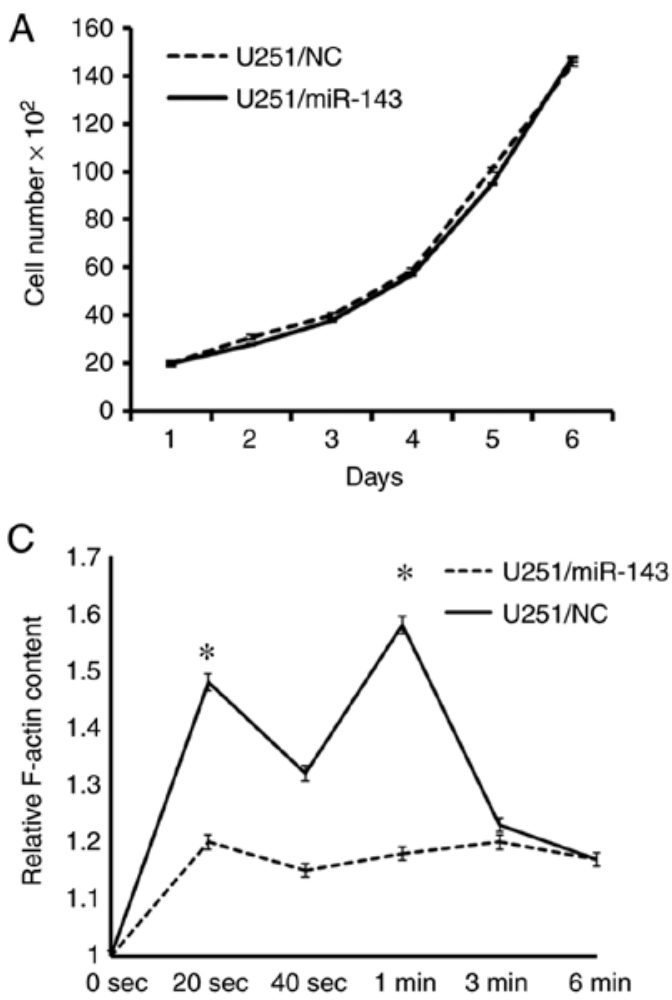
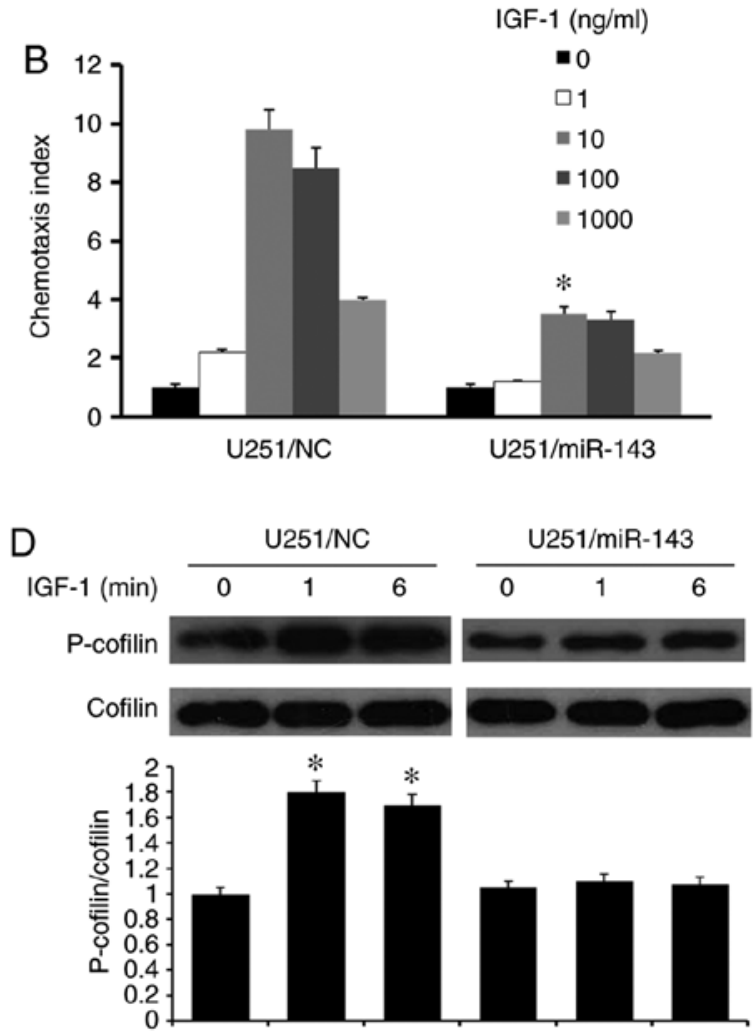

Figure 3. miR-143 promotes migration in glioma cells. (A) Comparison of cell viability in U251/NC and U251/miR-143. (B) Comparison of chemotactic responses with IGF-1 stimulation in U251 cells transfected with miR-143. (C) Time course of relative F-actin content in U251/NC and U251/miR-143 cells with $10 \mathrm{ng} / \mathrm{ml}$ of IGF-1 stimulation. (D) Western blotting of the phosphorylation of cofilin in total cell lysates from the control and the U251/miR-143 cells upon $10 \mathrm{ng} / \mathrm{ml}$ of IGF-1 stimulation for 0,1 and $5 \mathrm{~min}$, cofilin was used as a loading control. ${ }^{*} \mathrm{P}<0.05$. IGF, insulin growth factor; miR, microRNA; NC, negative control; p, phosphorylated.

Restoration of miR-143 in glioma cells inhibits cellular migration. To identify the effects of miR-143 on glioma cell migration, firstly, the cell viability rate in U251/miR-143 and $\mathrm{U} 251 / \mathrm{NC}$ cells was investigated, in vitro. The same number of U251/miR-143 and U251/NC cells were plated at the same time and cell numbers were counted at the following days. The result showed that increased miR-143 expression did not cause significant changes in cell viability (Fig. 3A). Following this, cell chemotaxis assay which was induced by IGF-1, was performed. The result suggested decreased chemotaxis in U251/miR-143 cells compared with U251/NC cells (Fig. 3B). The key to chemotaxis is ligand-induced cytoskeleton rearrangement (33). Quantitative F-actin polymerization assay revealed that IGF-1 induced transient actin polymerization at 20 and $60 \mathrm{sec}$ in U251/NC cells. Whereas in U251/miR-143 cells, F-actin polymerization was significantly reduced in spite of IGF-1 stimulation (Fig. 3C). These results indicated that miR-143 serves an important role in the migration of glioma cells.

Previous studies have proven that F-actin dynamics is regulated by phosphorylating cofilin at Ser3, which polymerizes actin, generates protrusions and determines the direction of cell migration (34). Thus, the phosphorylation level of cofilin in U251 cells was investigated. As shown in Fig. 3D, cofilin was rapidly activated by the IGF-1 at 1 and $6 \mathrm{~min}$. However, in the U251/miR-143 cells, the IGF-1-induced phosphorylation of cofilin was impaired. These results indicate that miR-143 is a key factor in the IGF-1-induced cofilin recycling.
Increased expression of miR-143 inhibits glioma cell invasion and migration. To verify our hypothesis that miR-143 serves an important role in glioma invasion through BMK1, scratch and Matrigel invasion assay were performed. The scratch assay is one of the few cell migration assays, which can be estimated at fixed time points (35). Several hours after wounding, it took U251/miR-143 cells a longer time to fill the gap, further supporting a defect in migration (Fig. 4A). Subsequently, Matrigel assay was performed and significant reductions of invasion by $48 \%$ in U251/miR-143 compared with the control cells was observed. However, there was no significant change in the invasion ability of U251/miR-143 inhibitor compared with U251/NC. For further confirmation, U251 cells were co-transfected with miR-143 and BMK1. As shown in Fig. 4B, the invasion ability of U251/miR-143+BMK1 recovered compared with U251/miR-143 (Fig. 4B). RT-qPCR results confirmed that the BMK1 expression was indeed increased in the U251/miR-143+BMK1 cells compared with the U251/miR-143 cells and U251/miR-143+CON cells (Fig. 4C). These results suggested that restoration of miR-143 inhibits the invasion and migration of glioma cells through BMK1.

miR-143 inhibits glioma invasion by downregulating BMK1 in vivo. To assess the biological functions of miR-143 and BMK1 in glioma in vivo, U87/NC and U87/miR-143 cells were implanted stereotactically into the brains of glioma-bearing mice $(n=8)$. The number of satellite tumors (tumor foci not 
A
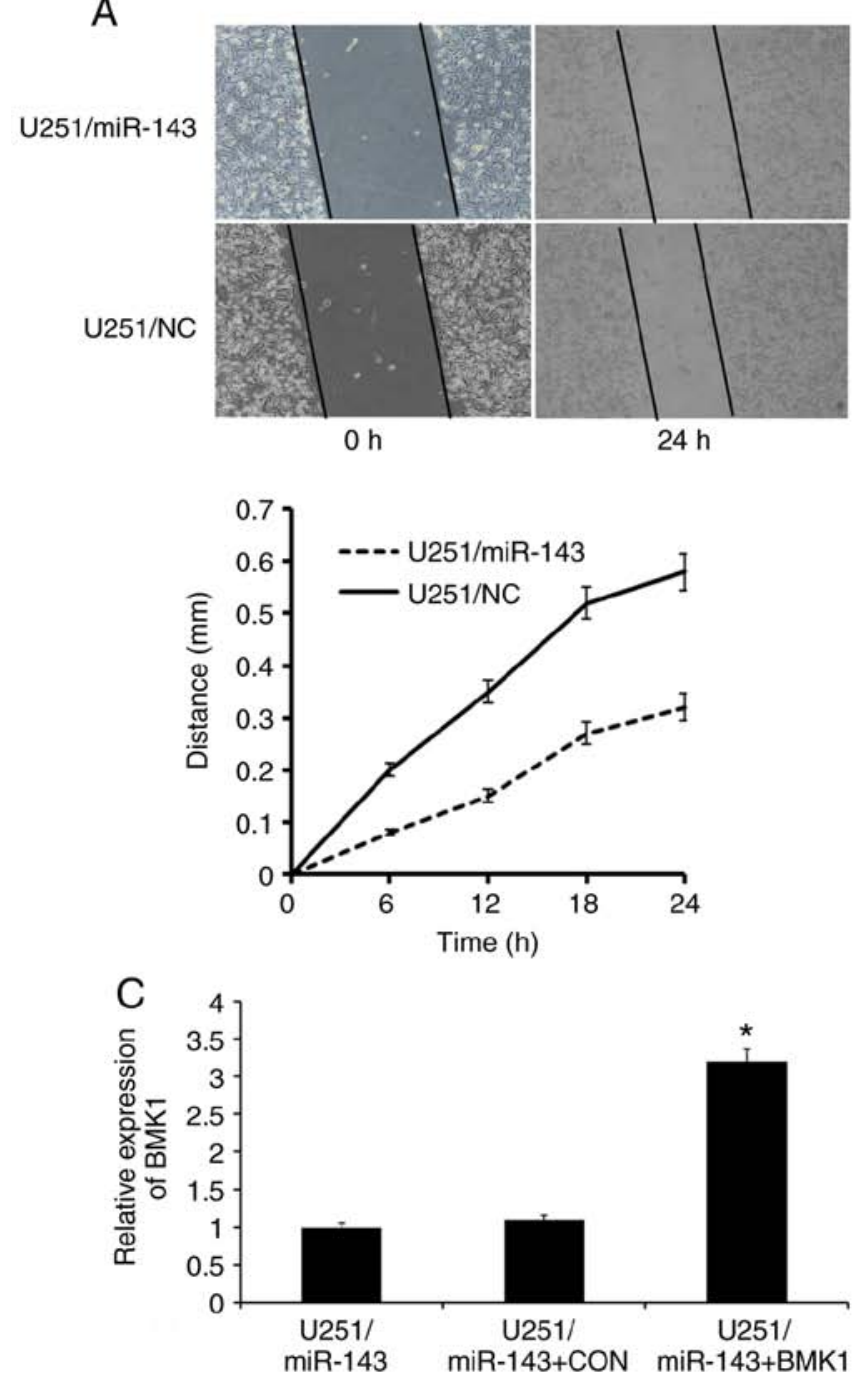

B

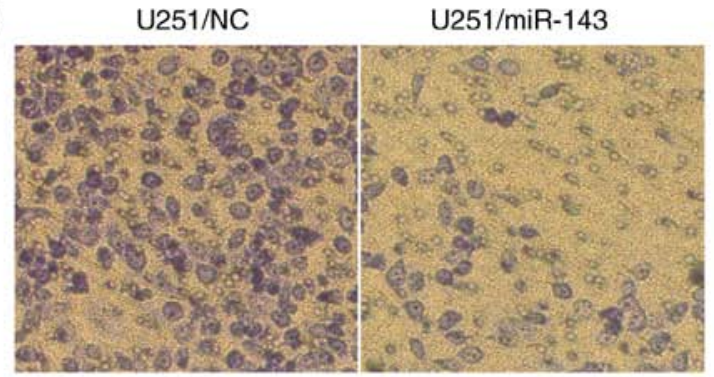

U251/miR-143 inhibitor

U251/miR-143+BMK1
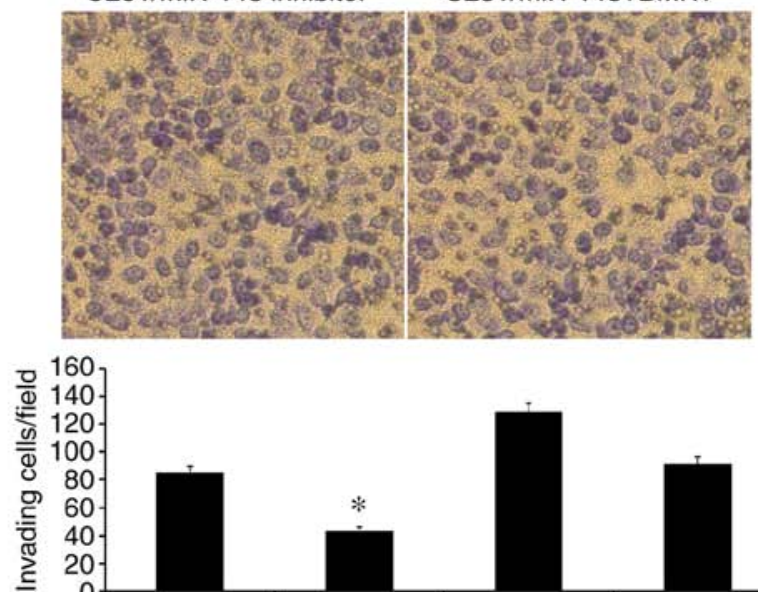

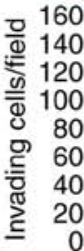

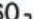

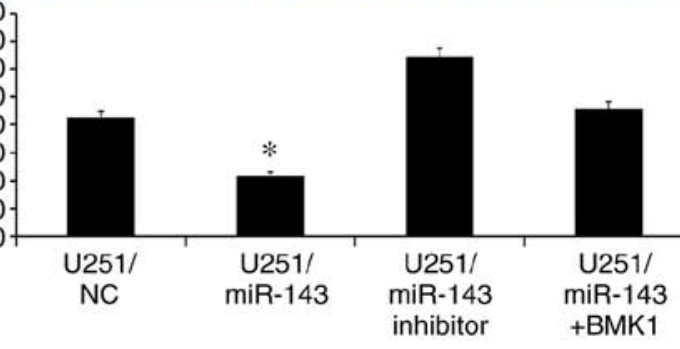

Figure 4. miR-143 enhanced glioma cells invasion. (A) Quantification of scratch assays on U251/NC, and U251/miR-143 cells. The distance of cell migration was measured. (B) Representative images of penetrated cells in U251/NC, U251/miR-143, U251/miR-143 inhibitor and U251/miR-143+BMK1 cells and quantification of the cells analyzed using the matrigel invasion assay. (C) Reverse transcription-quantitative polymerase chain reaction of BMK1 expression in cultured U251/miR-143, U251/miR-143+CON and U251/miR-143+BMK1. Scale bars $=50 \mu$ m. ${ }^{*} \mathrm{P}<0.05$. CON, control; BMK, big mitogen-activated kinase; miR, microRNA; NC, negative control.

connected with the main tumor) was regarded as a semi-quantitative measurement of tumor invasion (36). The number of satellite tumors which have migrated away from the main tumor mass or were projections from the main tumors was counted 30 days after tumor cell injection. As shown in Fig. 5A and B, the number of satellite tumors was less in the brains of mice injected with U87/miR-143 cells than that in the mice injected with U87/NC cells (10.1 vs. 31.7 satellite tumors per section, $\mathrm{P}<0.05$; Fig. $5 \mathrm{~B}$ ). The expression of BMK1 in the tumor xenograft was also investigated. As expected, BMK1 expression was lower in the mice injected with U87/miR-143 cells than in the mice injected with U87/NC cells (Fig. 5C). Taken together, these results indicate that miR-143 can significantly inhibit the expression of BMK1 and suppress the invasion of glioma cells, in vivo.

Downregulation of miR-143 in glioma cell lines and tissues is due to the DNA methylation. In mammals, DNA methylation serves a crucial role in the regulation of gene expression and chromatin structure. In many tumors, decreased miRNA expression is due to the hypermethylation of the promoter region (37). To verify this hypothesis, we explored the methylation level of miR-143 in both glioma cell lines and tissues. The results showed that the methylation level of miR-143 in genomic DNA obtained from glioma cell lines and clinical tissue samples was higher than that from NHA cell line. Notably, it also showed a tendency associated with WHO grading, strongly demonstrated that promoter methylation serves an important role in miR-143 downregulation (Fig. 6A).

To further explore the effect of DNA methylation, the NHA cell line and glioma cell lines were treated with a DNA methylation inhibitor 5-AZA-dC and found that it promoted the expression of miR-143 (Fig. 6B). Additionally, the inhibition of DNA methylation significantly inhibited the invasive ability of U87, U251 and SHG44 cells (Fig. 6C). In summary, these findings strongly suggested that the expression of miR-143 was regulated by DNA methylation in glioma cells and tissues. 
A

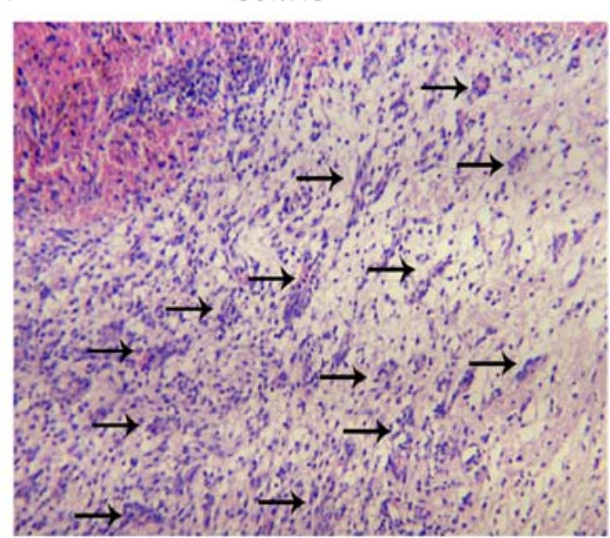

$\mathrm{U} 87 / \mathrm{miR}-143$

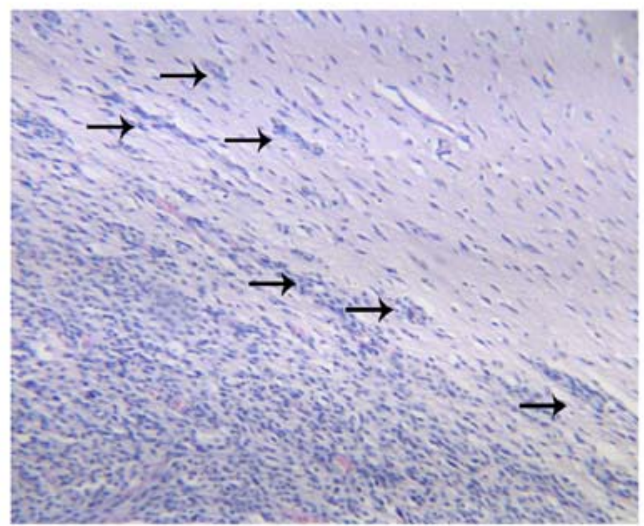

C
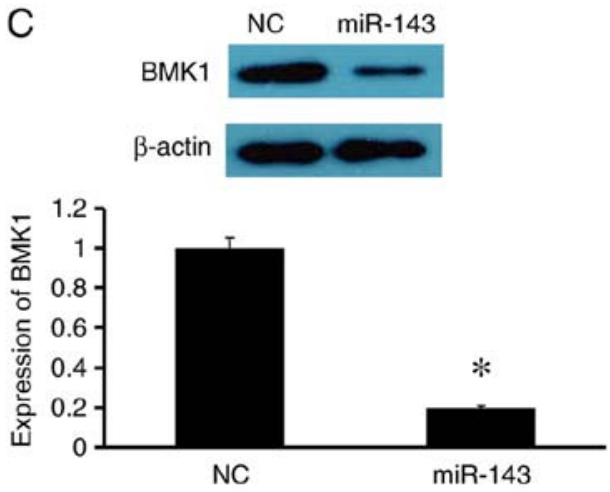

Figure 5. miR-143 inhibits glioma invasion by downregulating BMK1 in vivo. (A) Human tumor foci on severe immunodeficient mice brains implanted with U87/NC and U87/miR-143 were visualized by H\&E staining. (B) The number of satellite tumors (tumor foci not connected to main body of tumor) was counted and plotted $(\mathrm{n}=8)$. ${ }^{*} \mathrm{P}<0.05$. (C) Western blot analysis of BMK1 in implanted tumors of the mice injected with U87/NC cells and U87/miR-143 cells. Scale bars $=50 \mu \mathrm{m}$. ${ }^{*} \mathrm{P}<0.05$. Data are presented as the mean \pm standard deviation from three independent experiments. BMK, big mitogen-activated kinase; miR, microRNA; NC, negative control.
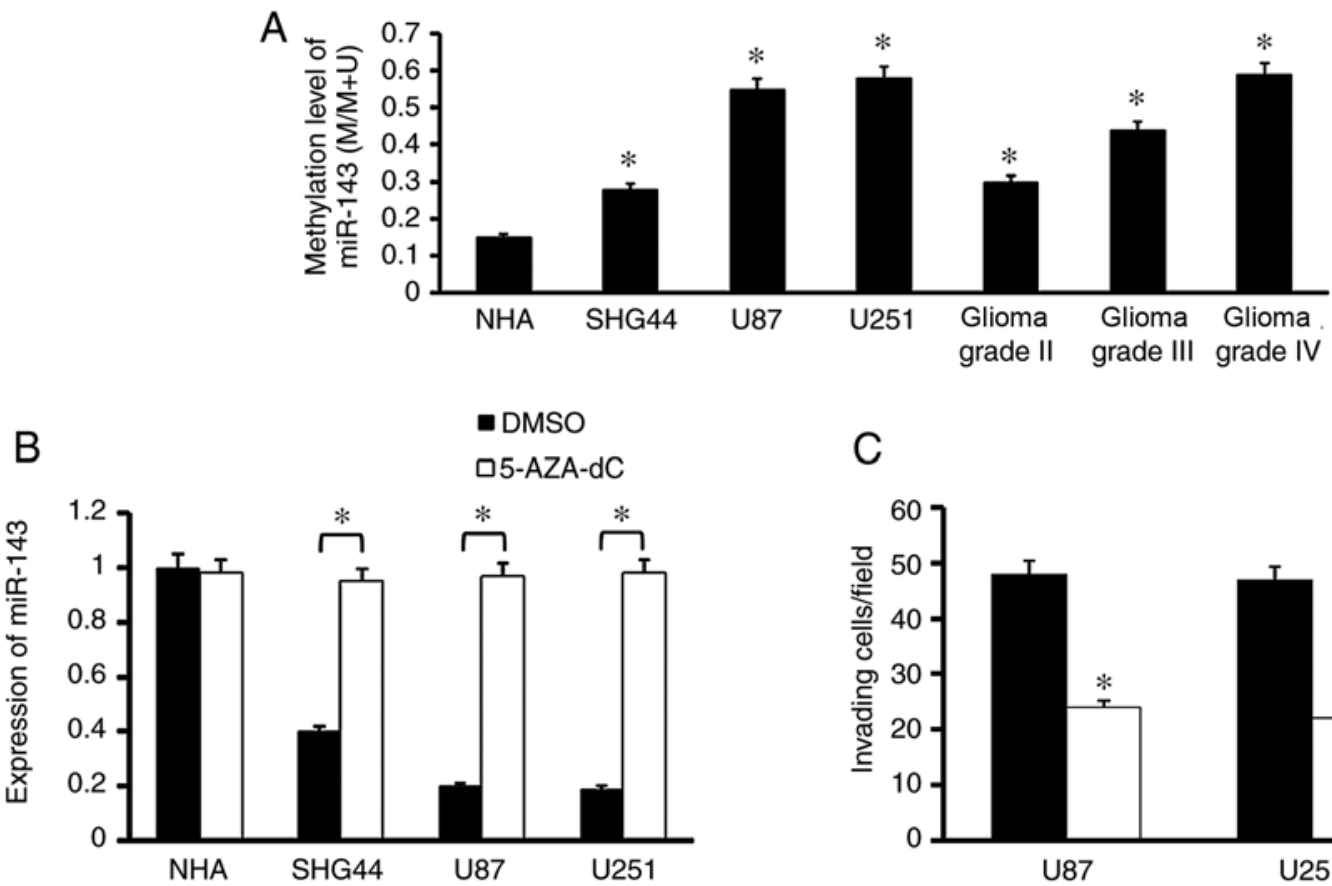

C

- DMSO

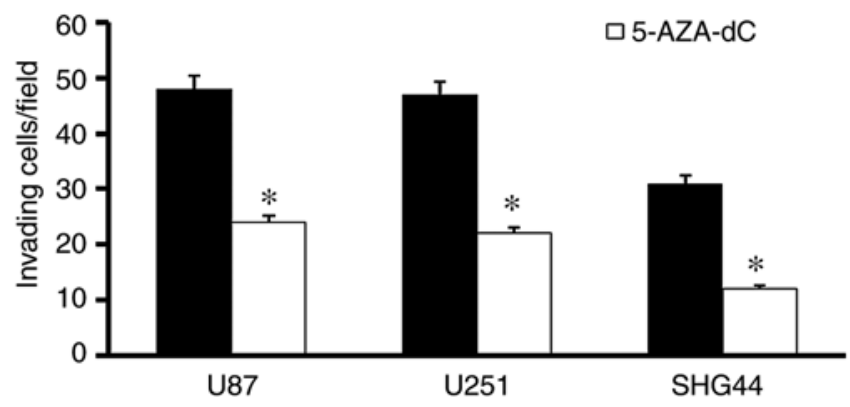

Figure 6. Downregulation of miR-143 is due to hypermethylation of its promoter. (A) The methylation level of miR-143 genomic region in indicated NHA, glioma cell lines, and in glioma specimens. (B) Reverse transcription-quantitative polymerase chain reaction of miR-143 expression in indicated cells treated with $5 \mu \mathrm{m}$ 5-aza-dC or DMSO for $72 \mathrm{~h}$. (C) Invasive abilities of U87, U251 and SHG44 cells with $5 \mu \mathrm{M} 5$-aza-dC or DMSO treatment for $72 \mathrm{~h}$. Data are presented as the mean \pm standard deviation from three independent experiments. ${ }^{*} \mathrm{P}<0.05$. miR, microRNA. 


\section{Discussion}

Recent reports suggest that miRNA-143 inhibits cell proliferation, invasion and metastasis by regulating multiple target genes (16). The present study provided the first evidence that miR-143 expression was significantly low in glioma tissues and cell lines. In particular, it was demonstrated that the expression of miR-143 had a strong association with the WHO grade and survival rates in patients with glioma.

In a previous study, BMK1 was highly expressed in glioma tissues and cell lines. It promoted the invasion and migration of glioma cells acting as a predictor of poor prognosis for patients with glioma (5). In the present study, miR-143 was predicted to act as a novel BMK1 suppressor. By transduction of miR-143 into glioma cells, it was demonstrated that miR-143 could repress BMK1 expression. Furthermore, 3'UTR luciferase assay and RIP analysis confirmed that miR-143 inhibited BMK1 via direct binding to the 3'UTR of BMK1.

Polarized cell migration, which is tightly regulated during tissue development, chemotaxis and wound healing, is highly associated with the tumors infiltration and invasion (38). In the present study, the restoration of miR-143 in the chemotaxis, wound healing and matrigel invasion assay severely impaired the migration and invasive ability of glioma cell lines. This result suggested that miR-143 may be an essential factor in glioma cell migration and invasion. The rescue assays drew the conclusion that miR-143 inhibited glioma invasion by downregulating BMK1. Actin polymerization and the subsequent formation of membrane protrusions are necessary for polarized cell migration. Actin regulates the motility of cancer cell through cytoskeletal rearrangement (39). Previous studies have proven that F-actin dynamics are regulated by phosphorylating cofilin at Ser3 (34). The present results demonstrated that miR-143 participated in the IGF-1-induced F-actin polymerization to mediate cytoskeletal rearrangement, which is vital in glioma cell migration and invasion. Furthermore, miR-143 is a key factor in the IGF-1-induced cofilin recycling. Therefore, it may be speculated that overexpression of miR-143 downregulated the expression of BMK1, which in turn regulated the phosphorylation of cofilin and F-actin polymerization.

A previous study showed that miR-143 could inhibit viability of A172 cells (40). In the present study, increased miR-143 expression did not cause significant changes in cell viability. The potential reasons of this distinction include different glioma cell lines, different cell density and different observed time. In addition, downregulation of miR-143 expression did not significantly enhance the invasion ability of glioma cell lines. The reason may be that the cell lines used were highly invasive glioblastoma cell lines, which is hard to further increase the invasion.

Epigenetic modifications have been shown to display a tight association with carcinogenesis and to serve an important role in miRNA expression $(41,42)$. The present data suggested that decreased miR-143 expression is due to the hypermethylation of the upstream promoter region in glioma cell lines and tissues. This conclusion was confirmed through treatment with 5-aza-dC, a DNA methyltransferase inhibitor, which restored miR-143 expression in glioma cell lines and reduced the invasion of cancer cells. Based on these findings, the methylation status of miR-143 may serve as a potential biomarker for the prognosis of glioma, but this needs to be further verified.

In summary, miR-143 expression levels were lower in glioma cells and that miR-143 inhibited glioma cell invasion and migration. The molecular mechanisms of miR-143 and BMK1 mediating in cells migration and invasion was also investigated. Future studies could examine the therapeutic potential of miR-143 and identify additional genome-wide targets of this microRNA.

\section{Acknowledgements}

Not applicable.

\section{Funding}

The present study was supported by the National Natural Scientific Foundation of China (grant nos. 81872163, 81672631, 81072068, 81472365, and 81501185), The Young and Middle-Aged Scientists Research Awards Foundation of Shandong Province (grant no. 2010BSB14050), Foundation of Shandong Educational Committee (grant no. J14LK13), Scientific Foundation of Shandong Province (grant nos. ZR2017PH079, ZR2014HM003, and ZR2015HM028), Shandong Provincial Key Research \& Development Project (grant no. 2017GSF218043). Shandong Province outstanding youth scientist foundation plan (grant no. BS2013YY020).

\section{Availability of data and materials}

The analyzed data sets generated during the study are available from the corresponding author on reasonable request.

\section{Authors' contributions}

BZ conceived and designed the present study. BZ, WYC, ZQL, $\mathrm{CR}$ and PY performed the experiments and analyzed data. All authors have read and approved the final manuscript.

\section{Ethics approval and consent to participate}

Samples were collected following a protocol approved by the Institutional Review Board, and patients gave their consent for the research of their tissue specimens in the present study. The study protocol was reviewed and approved by the Weifang Medical University Ethics Committee (approval no 99, 11-November-2016). The study protocol for the xerograph study in mice was reviewed and approved by Weifang Medical University Ethics Committee (approval no 129, 11-November-2016).

\section{Patient consent for publication}

Written informed consent for publication was obtained from all patients.

\section{Competing interests}

The authors declare that they have no competing interests. 


\section{References}

1. Rousseau A, Mokhtari K and Duyckaerts C: The 2007 WHO classification of tumors of the central nervous system-what has changed? Curr Opin Neurol 21: 720-727, 2008

2. Ohgaki $\mathrm{H}$ and Kleihues P: Genetic pathways to primary and secondary glioblastoma. Am J Pathol 170: 1445-1453, 2007.

3. Demuth T and Berens ME: Molecular mechanisms of glioma cell migration and invasion. J Neurooncol 70: 217-228, 2004.

4. Shukla A, Miller JM, Cason C, Sayan M, MacPherson MB, Beuschel SL, Hillegass J, Vacek PM, Pass HI and Mossman BT: Extracellular signal-regulated kinase 5: A potential therapeutic target for malignant mesotheliomas. Clin Cancer Res 19 2071-2083, 2013

5. Chen W, Zhang B, Guo W, Gao L, Shi L, Li H, Lu S, Liu Y and Li X: miR-429 inhibits glioma invasion through BMK1 suppression. J Neurooncol 125: 43-54, 2015.

6. Song C, Wang L, Xu Q, Wang K, Xie D, Yu Z, Jiang K, Liao L, Yates JR, Lee JD and Yang Q: Targeting BMK1 impairs the drug resistance to combined inhibition of BRAF and MEK1/2 in melanoma. Sci Rep 7: 46244, 2017.

7. Rovida E, Di Maira G, Tusa I, Cannito S, Paternostro C, Navari N, Vivoli E, Deng X, Gray NS, Esparís-Ogando A, et al: The mitogen-activated protein kinase ERK5 regulates the development and growth of hepatocellular carcinoma. Gut 64 $1454-1465,2015$

8. Lagos-Quintana M, Rauhut R, Lendeckel W and Tuschl T: Identification of novel genes coding for small expressed RNAs Science 294: 853-858, 2001.

9. Zhao L, Sun Y, Hou Y, Peng Q, Wang L, Luo H, Tang X, Zeng Z and Liu M: miRNA expression analysis of cancer-associated fibroblasts and normal fibroblasts in breast cancer. Int J Biochem Cell Biol 44: 2051-2059, 2012.

10. Ying Z, Li Y, Wu J, Zhu X, Yang Y, Tian H, Li W, Hu B, Cheng SY and $\mathrm{Li} \mathrm{M}$ : Loss of miR-204 expression enhances glioma migration and stem cell-like phenotype. Cancer Res 73: 990-999, 2013

11. Lim LP, Lau NC, Garrett-Engele P, Grimson A, Schelter JM, Castle J, Bartel DP, Linsley PS and Johnson JM: Microarray analysis shows that some microRNAs downregulate large numbers of target mRNAs. Nature 433: 769-773, 2005.

12. Krek A, Grun D, Poy MN, Wolf R, Rosenberg L, Epstein EJ, MacMenamin P, da Piedade I, Gunsalus KC, Stoffel $M$ and Rajewsky N: Combinatorial microRNA target predictions. Nat Genet 37: 495-500, 2005

13. Lu J, Getz G, Miska EA, Alvarez-Saavedra E, Lamb J, Peck D, Sweet-Cordero A, Ebert BL, Mak RH, Ferrando AA, et al: MicroRNA expression profiles classify human cancers. Nature 435: 834-838, 2005.

14. Garzon R, Calin GA and Croce CM: MicroRNAs in cancer. Annu Rev Med 60: 167-179, 2009.

15. Michael MZ, O'Connor SM, van Holst Pellekaan NG, Young GP and James RJ: Reduced accumulation of specific microRNAs in colorectal neoplasia. Mol Cancer Res 1: 882-891, 2003.

16. Motoyama K, Inoue $\mathrm{H}$, Takatsuno $\mathrm{Y}$, Tanaka F, Mimori K, Uetake H, Sugihara K and Mori M: Over- and under-expressed microRNAs in human colorectal cancer. Int $\mathbf{J}$ Oncol 34: 1069-1075, 2009.

17. Bandres E, Cubedo E, Agirre X, Malumbres R, Zárate R, Ramirez N, Abajo A, Navarro A, Moreno I, Monzó M and García-Foncillas J: Identification by Real-time PCR of 13 mature microRNAs differentially expressed in colorectal cancer and non-tumoral tissues. Mol Cancer 5: 29, 2006.

18. Schepeler T, Reinert JT, Ostenfeld MS, Christensen LL, Silahtaroglu AN, Dyrskjøt L, Wiuf C, Sørensen FJ, Kruhøffer M, Laurberg S, et al: Diagnostic and prognostic microRNAs in stage II colon cancer. Cancer Res 68: 6416-6424, 2008.

19. Papaconstantinou IG, Manta A, Gazouli M, Lyberopoulou A, Lykoudis PM, Polymeneas G and Voros D: Expression of microRNAs in patients with pancreatic cancer and its prognostic significance. Pancreas 42: 67-71, 2013.

20. Takagi T, Iio A, Nakagawa Y, Naoe T, Tanigawa N and Akao Y: Decreased expression of microRNA-143 and -145 in human gastric cancers. Oncology 77: 12-21, 2009.

21. Sun L, Zhang B, Liu Y, Shi L, Li H and Lu S: miR125a-5p acting as a novel Gab2 suppressor inhibits invasion of glioma. Mol Carcinog 55: 40-51, 2016
22. Livak KJ and Schmittgen TD: Analysis of relative gene expression data using real-time quantitative PCR and the 2(-Delta Delta C(T)) method. Methods 25: 402-408, 2001.

23. Ufkin ML, Peterson S, Yang X, Driscoll H, Duarte C and Sathyanarayana P: miR-125a regulates cell cycle, proliferation, and apoptosis by targeting the ErbB pathway in acute myeloid leukemia. Leuk Res 38: 402-410, 2014.

24. Jiang L, Lin C, Song L, Wu J, Chen B, Ying Z, Fang L, Yan X, $\mathrm{He}$ M, Li J and Li M: MicroRNA-30e" promotes human glioma cell invasiveness in an orthotopic xenotransplantation model by disrupting the $\mathrm{NF}-\kappa \mathrm{B} / \mathrm{I} \kappa \mathrm{B} \alpha$ negative feedback loop. J Clin Invest 122: 33-47, 2012.

25. Li H, Yin C, Zhang B, Sun Y, Shi L, Liu N, Liang S, Lu S, Liu Y, Zhang J, et al: PTTG1 promotes migration and invasion of human non-small cell lung cancer cells and is modulated by miR-186. Carcinogenesis 34: 2145-2155, 2013.

26. Li J, Tu Y, Wen J, Yao F, Wei W and Sun S: Role for ezrin in breast cancer cell chemotaxis to CCL5. Oncol Rep 24: 965-971, 2010.

27. Wang LH, Xiang J, Yan M, Zhang Y, Zhao Y, Yue CF, Xu J, Zheng FM, Chen JN, Kang Z, et al: The mitotic kinase Aurora-A induces mammary cell migration and breast cancer metastasis by activating the Cofilin-F-actin pathway. Cancer Res 70: 9118-9128, 2010.

28. Hall EH, Gurel V, Dahlberg AE, McMichael J and Brautigan DL: Inhibition of human breast cancer Matrigel invasion by Streptolysin O activation of the EGF receptor ErbB1. Cell Signal 23: 1972-1977, 2011.

29. Tan LP, Seinen E, Duns G, de Jong D, Sibon OC, Poppema S, Kroesen BJ, Kok K and van den Berg A: A high throughput experimental approach to identify miRNA targets in human cells. Nucleic Acids Res 37: e137, 2009.

30. Cheng GZ, Zhang W and Wang LH: Regulation of cancer cell survival, migration, and invasion by Twist: AKT2 comes to interplay. Cancer Res 68: 957-960, 2008.

31. Shi L, Sun X, Zhang J, Zhao C, Li H, Liu Z, Fang C, Wang X, Zhao C, Zhang X, et al: Gab2 expression in glioma and its implications for tumor invasion. Acta Oncol 52: 1739-1750, 2013.

32. Villa C, Miquel C, Mosses D, Bernier M and Di Stefano AL: The 2016 World Health Organization classification of tumours of the central nervous system. Presse Med 47: e187-e200, 2018.

33. He Y, Li D, Cook SL, Yoon MS, Kapoor A, Rao CV, Kenis PJ, Chen $\mathbf{J}$ and Wang F: Mammalian target of rapamycin and Rictor control neutrophil chemotaxis by regulating $\mathrm{Rac} / \mathrm{Cdc} 42$ activity and the actin cytoskeleton. Mol Biol Cell 24: 3369-3380, 2013.

34. Ghosh M, Song X, Mouneimne G, Sidani M, Lawrence DS and Condeelis JS: Cofilin promotes actin polymerization and defines the direction of cell motility. Science 304: 743-746, 2004.

35. Etienne-Manneville $S$ and Hall A: Integrin-mediated activation of $\mathrm{Cdc} 42$ controls cell polarity in migrating astrocytes through PKCzeta. Cell 106: 489-498, 2001.

36. Tran TT, Uhl M, Ma JY, Janssen L, Sriram V, Aulwurm S, Kerr I, Lam A, Webb HK, Kapoun AM, et al: Inhibiting TGF-beta signaling restores immune surveillance in the SMA-560 glioma model. Neuro Oncol 9: 259-270, 2007.

37. Yim RL, Wong KY, Kwong YL, Loong F, Leung CY, Chu R, Lam WW, Hui PK, Lai R and Chim CS: Methylation of miR-155-3p in mantle cell lymphoma and other non-Hodgkin's lymphomas. Oncotarget 5: 9770-9782, 2014.

38. Noritake J, Watanabe T, Sato K, Wang S and Kaibuchi K: IQGAP1: A key regulator of adhesion and migration. J Cell Sci 118: 2085-2092, 2005.

39. Zhang B, Gu F, She C, Guo H, Li W, Niu R, Fu L, Zhang N and Ma Y: Reduction of Akt2 inhibits migration and invasion of glioma cells. Int J Cancer 125: 585-595, 2009.

40. Fu TG, Wang L, Li W, Li JZ and Li J: miR-143 inhibits oncogenic traits by degrading NUAK2 in glioblastoma. Int J Mol Med 37: 1627-1635, 2016

41. Wynter CV: The dialectics of cancer: A theory of the initiation and development of cancer through errors in RNAi. Med Hypotheses 66: 612-635, 2006.

42. Ren X, McHale CM, Skibola CF, Smith AH, Smith MT and Zhang L: An emerging role for epigenetic dysregulation in arsenic toxicity and carcinogenesis. Environ Health Perspect 119: $11-19,2011$ 